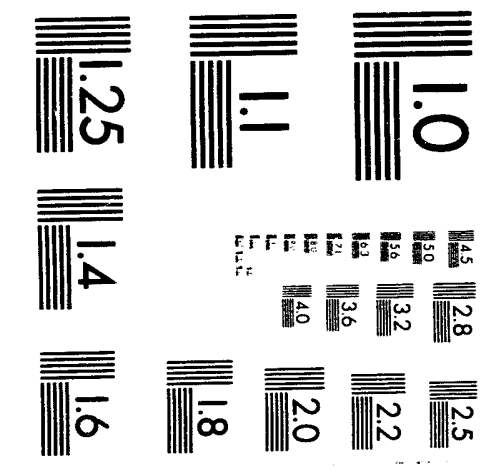



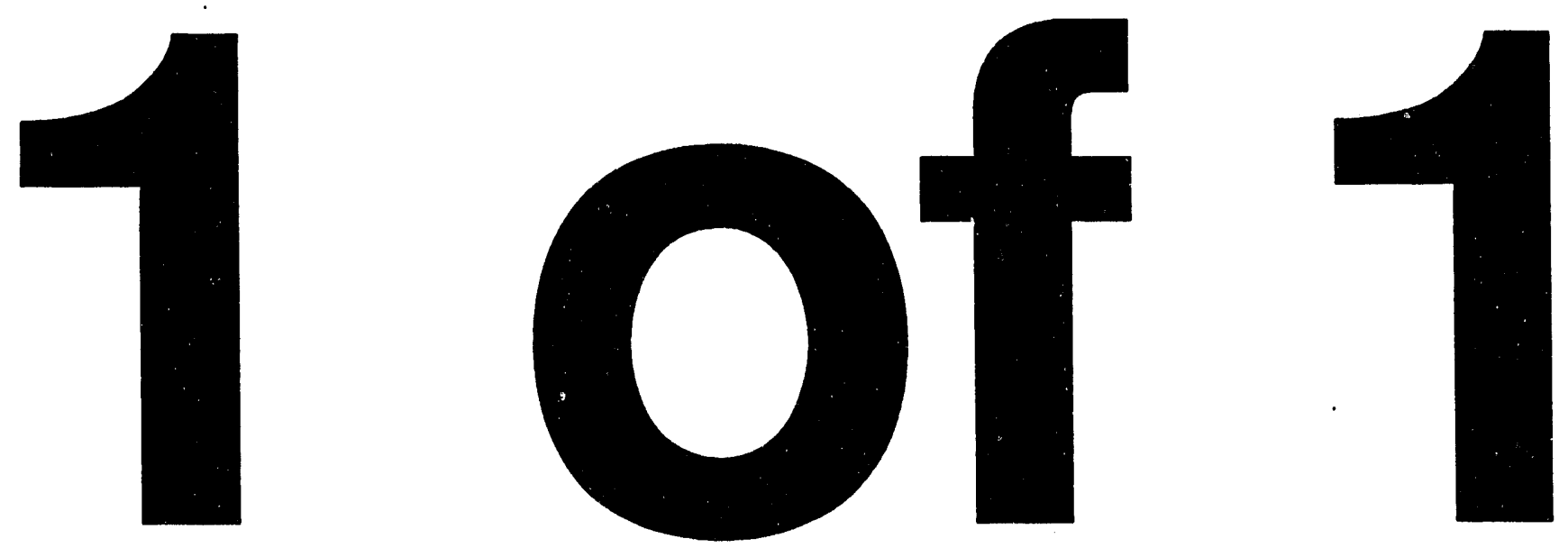
'The submitted manuscript has been authored by a contractor of the U.S. Government under contract No. DE-AC05-84OR21400.

Accordingly, the U.S. Government retains a nonexclusive, royalty-free license to publish or reproduce the published form of this contribution, or allow others to do so, for U.S. Government purposes."

$$
\text { Contf }-931018-6.5
$$

\title{
Design of Folded Waveguide Antenna for Alcator C-Mod
}

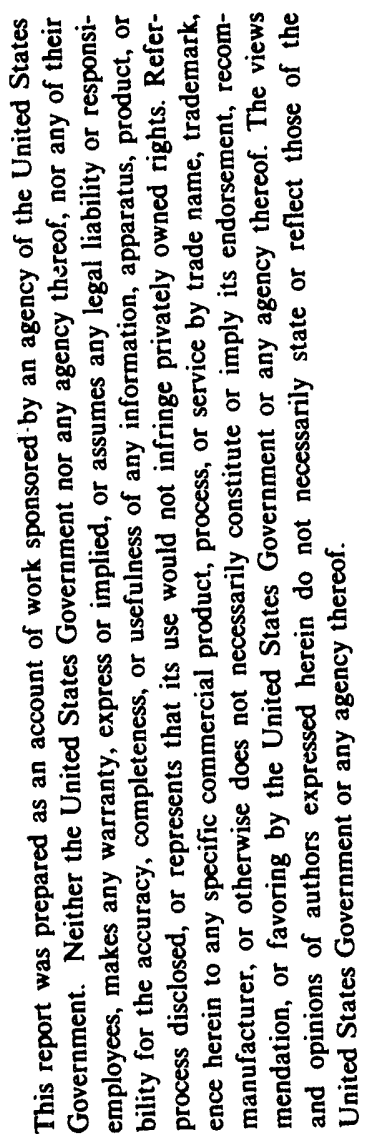

\author{
B y \\ C. H. Fogelman, T. S. Bigelow, M. D. Carter, \\ D. J. Hoffman, B. W. Riemer, J. J. Yugo
}

S. Golovato and P. Bonoli

Massachusetts Institute of Technology

Plasma Fusion Center

167 Albany Street

Cambridge, MA 02139

Presented at
IEEE/NPSS 15th Symposium

on Fusion Engineering

Hyannis, MA

October 11-15, 1993

\author{
Prepared for the \\ Fusion Energy Division
}

Prepared by

Oak Ridge National Laboratory

Post Office Box 2008

Oak Ridge, TN 37831-6285 USA

Managed by

MARTIN MARIETTA ENERGY SYSTEMS, INC. for the

U.S. DEPARTMENT OF ENERGY

under contract DE-AC05-84OR21400

* Research sponsored by the Office of Fusion Energy, U.S. Department of Energy, under contract DE-AC05-84OR21400 with Martin Marietta Energy Systems, Inc. 


\title{
Design of Folded Waveguide Antenna for Alcator C-Mod*
}

\author{
C. H. Fogelman, T. S. Bigelow, M. D. Carter, D. J. Hoffman, B. W. Riemer, J. J. Yugo \\ Oak Ridge National Laboratory, Oak Ridge, Tennessee, 37831-8071, USA
}

S. N. Golovato, P. Bonoli

MIT Plasma Fusion Center, 175 Albany Street, Cambridge, MA 02139, USA

\begin{abstract}
The Oak Ridge National Laboratory (ORNL) lon cyclotron range of frequencles (ICRF) antenna for Alcator C-Mod is a folded waveguide (FWG) antenna designed to determine whether the FWG can serve as a high power density, ceramic-free antenna for both present heating and fast wave current drive (FWCD) applications and for future tokamaks such as the International Thermonuclear Experimental Reactor (ITER) and the Tokamak Physics Experiment (TPX). The FWG is particularly attractive because it has a low internal electric field per unit power coupled to the plasma. This results in more power capability and has been demonstrated by 1-MW (unloaded) tests on the Radio Frequency Test Faclity (RFTF). The experiment will characterize the impact of an FWG on impurity control in the presence of high power density and on central heating.

The antenna is designed to withstand the tokamak environment, including high heat fluxes, high-temperature bakeout, and major disruptions, without vacuum leaks. The front face is curved to fit the plasma outline. Two front plates are fabricated for the antenna, one with full-width slits at every other location between vanes and the other with alternating right and left half-width slits at every location between vanes for pl-phasing.
\end{abstract}

\section{DESCRIPTION}

The folded waveguide (FWG) is a stainless steel or Inconel 625 box, 190 num wide $\times 425 \mathrm{~mm}$ high $\times 3700 \mathrm{~mm}$ long, with 13 alternating internal longitudinal vanes. It has a front face curved to conform to the plasma outline with full-width slits at every other location batween vanes. An orthogonal back plate serves as a shortin's rlate. All inside surfaces are copperplated.

The size and shrpe of the FWG make welding and plating as an assembly difficult. Construction consists of drilled plates stacked to form the configuration and bolted together with long socket-head cap screws through the side walls (Fig. 1). The plates can be copper-plated individually before assembly to ensure even coverage. The front and back plates are bolted on with small screws. On the front end, each vane edge is machined with a $0.127-\mathrm{mm}$ lip to enable good surface electrical contact between the vane and the front plate. The front plate is plated front and back and coated with boron carbide on the front. Bumpers of tantalum, zirconium, and molybdenum (TZM) bolt to the top at the front of the FWG. To minimize the width of the FWG, the side bumpers are substituted for the front $50.8 \mathrm{~mm}$ of material on the side plates (Fig. 2).

\footnotetext{
${ }^{*}$ Research sponsored by the Office of Fusion Energy, U.S Department of Energy, under contract DE-AC05-84OR21400 with Martin Marietta Energy Systems, Inc.
}

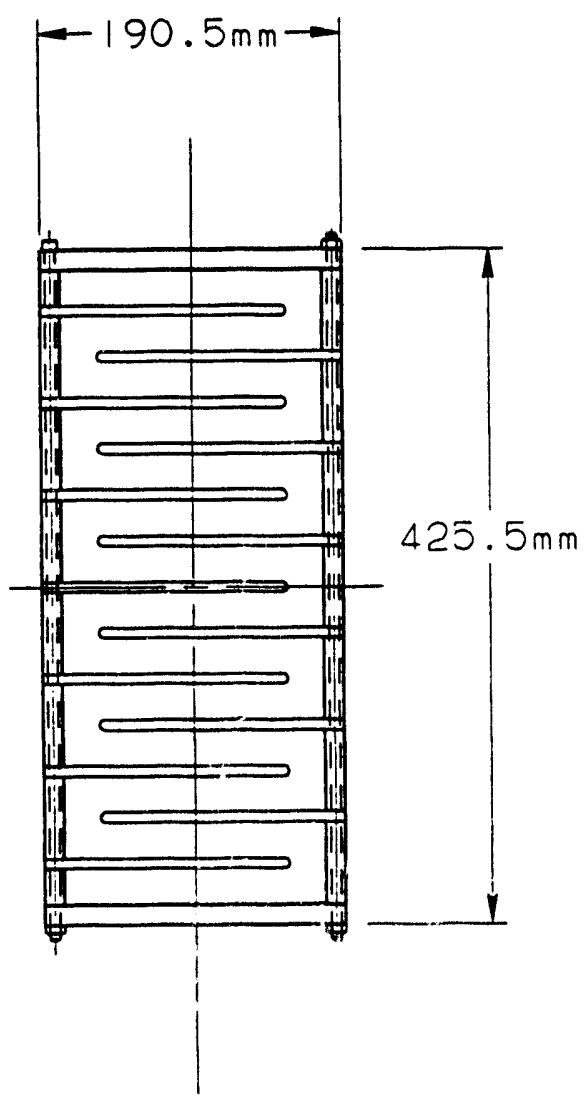

Fig. 1 Cross sertion of folded waveguide.

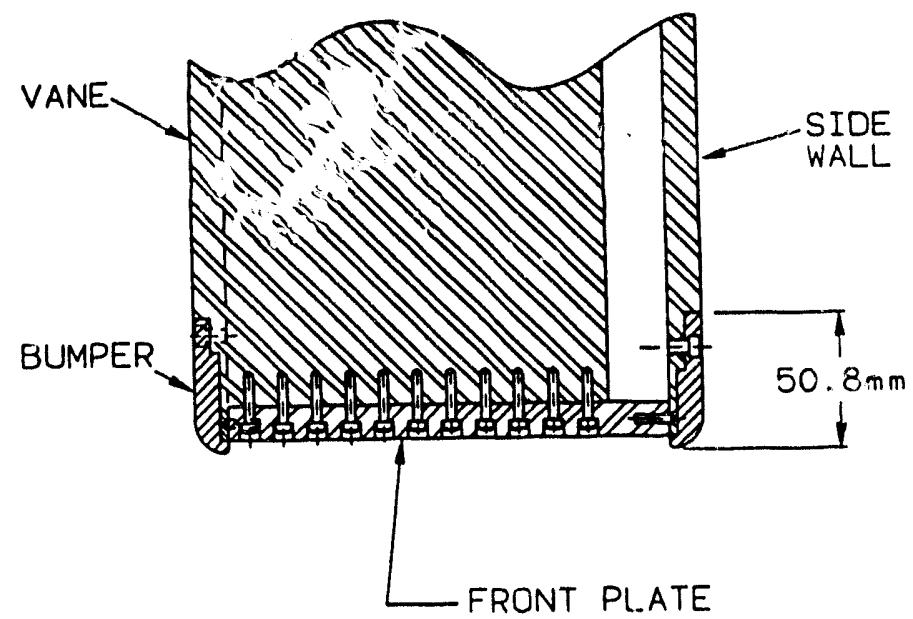

Fig. 2 Bumper mounting. 
The FWG is installed on one of the 8-in. ports of the Alcator C-Mod at Massachusetts Institute of Technology (Fig. 3). A second vacuum vessel extension is necessary to move the vacuum vessel/waveguide housing interface beyond the igloo. The waveguide housing is a cylindrical vessel sized to contain the FWG and the coax. An adapter flange accommodates the dissimilar bolt patterns and seals of the extension flange and the vacuum housing flange. A separate vacuum system is provided for the waveguide housing volume.

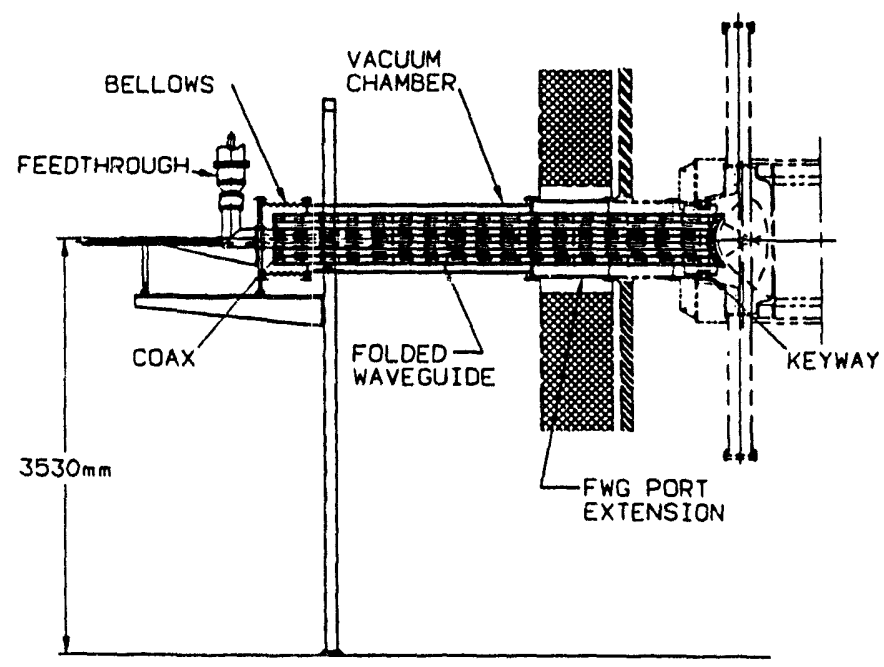

Fig. 3 Elevation of folded waveguide installed on Alcator C-Mod.

The FWG is tunable via a sliding electrical contact between the center vane and the inner conductor of a 6.25 -in. coax bolted to the longitudinal slot in the side wall. The sliding feed consists of a U-shaped vane toucher attached to a split collar bolted around the inner conductor of the coax. All sliding electrical contact is made with finger stock (Fig. 4). The feed is positioned by linear motion of a ceramic rod centered on the sliding feed assembly and driven through its 890-mm stroke within a welded bellows by a linear actuator.

The FWG is movable radially $5 \mathrm{~mm}$ in and $95 \mathrm{~mm}$ out from a nominal position of $5 \mathrm{~mm}$ behind the leading edge of the C-Mod limiter. Retention of the YWG using a keyway allows the FWG to slide radially without binding. A bellows between the waveguide housing back flange and the port cover flange allows relative motion of the FWG in the housing. A dual screw jack drive system is mounted on a plate attached to the back flange of the waveguide housing. The jack screw load pads are bolted to ears on the port cover flange, which is bolted to the FWG.

The radio frequency ( $\mathrm{rf}$ ) feedthrough is mounted to an elbow to provide an exit for the sliding feed drive rod. The feedthrough is a modified version of another antenna feedthrough and provides a transition from the 6.25 -in. to the 9-in. coax.

The FWG is supported by a key in the front and rollers in the back that ride on rails welded to the vacuum enclosure.

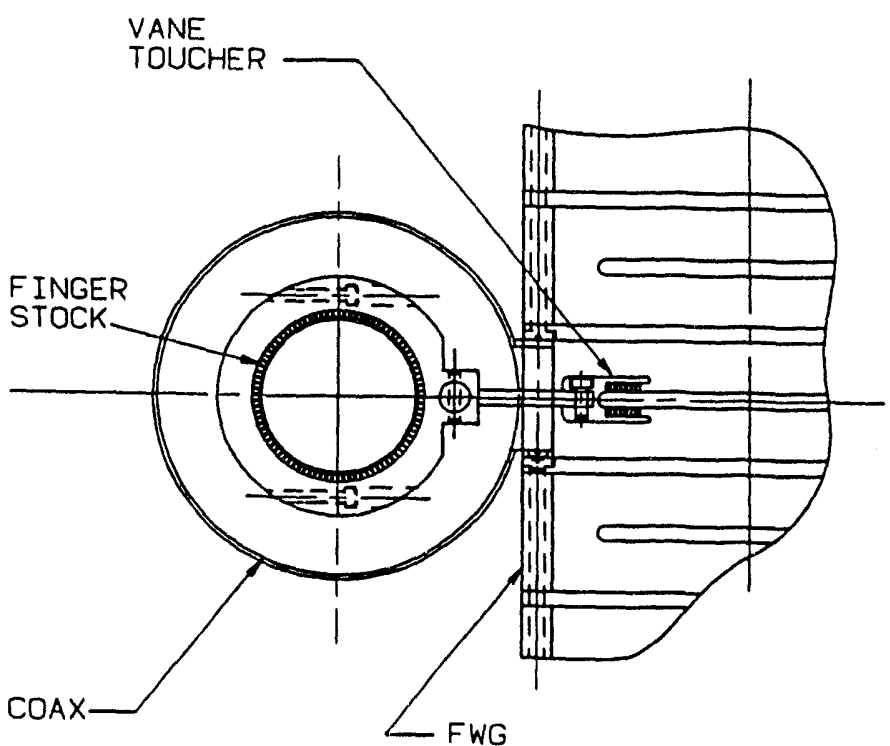

Fig. 4 Slide tuning subassembly.

The vacuum enclosure is supported by an aluminum frame bolted to the floor. Instrumentation of the FWG includes if voltage and current probes and thermocouples. The FWG is outfitted with heaters for bakeout. All instrumentation and heater feedthroughs are on the port cover flange.

\section{DISRUPTION LOAD ANALYSIS}

Disruption loads on the FWG are based on a $1 \mathrm{MA} / \mathrm{ms}$ vertical disruption with a 3-MA initial current and a 9-T toroidal field. The loads were calculated using the SPARK program. The FW/G model consists of the $12.7-\mathrm{mm}$-thick sides of the boix with five 6.4-mm-thick vanes: a pair at the top, a pair at the middle, and a single vane at the bottom. Two plates, one abov $\&$ and one below the middle pair of vanes, do not connect to the FWG sides but compensate for the crosssectional area of the eight vanes absent from the model. The Alcator C-Mod vacuum vessel geometry is included in the analysis.

The resultant disruption loads are summarized in Table I, where $x$ is radial and positive toward the machine, $z$ is vertical and positive up, and $y$ is perpendicular to $x$ and $z$. The loads all cecur in the front $300 \mathrm{~mm}$ of the FWG.

Table I

Disruption loads

\begin{tabular}{cll}
\hline Load direction & Stainless steel & Inconel 625 \\
\hline $\mathrm{Mx}$ & $57,000 \mathrm{~N}-\mathrm{m}$ & $34,000 \mathrm{~N} \cdot \mathrm{m}$ \\
$\mathrm{My}$ & $13,000 \mathrm{~N}-\mathrm{m}$ & $8,000 \mathrm{~N} \cdot \mathrm{m}$ \\
$\mathrm{Mz}$ & $13,000 \mathrm{~N} \cdot \mathrm{m}$ & $8,000 \mathrm{~N} \cdot \mathrm{m}$ \\
$\mathrm{Fx}$ & $160,000 \mathrm{~N}$ & $93,000 \mathrm{~N}$ \\
$\mathrm{Fy}$ & $+1-7,600 \mathrm{~N}$ & $+1.4,400 \mathrm{~N}$ \\
$\mathrm{Fz}$ & $+1-7,600 \mathrm{~N}$ & $+1-4,400 \mathrm{~N}$ \\
\hline
\end{tabular}




\section{STRESS ANALYSIS}

Nontorsional disruption loads on the FWG produce insignificant stresses: maximum bending stress and average shear are 11,000 and $400 \mathrm{kPa}$ for stainless steel and 6,500 and $200 \mathrm{kPa}$ for Inconel 625.

The torsion load is severe, but because it occurs only in the front $300 \mathrm{~mm}$ of the FWG, the torsion will be reacted by a force couple on the keys in the keyway. This induces shear and bending moments back across the FWG cross section. The stainless steel FWG endures a maximum torsional shear stress of $669,000 \mathrm{kPa}$. The reaction load at each key is $116,000 \mathrm{~N}$. For an Inconel $625 \mathrm{FWG}$, maximum torsional shear is $393,000 \mathrm{kPa}$, and the reaction load is $72,000 \mathrm{~N}$. Friction between the bolted surfaces prevents the long rods from loading up in shear, but they must be preloaded to provide adequate clamping force. To resist the side load in the stainless steel FWG, five high-strength bolts in the key area are required. Three bolts are needed for the Inconel 625 FWG.

Material selection is the primary remaining consideration. Stainless steel is readily available and machinable; because Inconel 625 is hard, drilling closely toleranced holes for the stack-up will be difficult. However, Inconel 625 has advantages for withstanding disruption. Its increased resistivity, which decreases loads, and its superior strength, which increases allowable stress, make it an attractive choice.

\section{THERMAL ANALYSIS}

The FWG is baked out at $150^{\circ} \mathrm{C}$ and then subjected to three sources of heat load during the 5 -s pulse at $20-\mathrm{min}$ intervals. The front face receives $30 \mathrm{~W} / \mathrm{cm}^{2}$ of plasma radiation. The rf losses of $161 \mathrm{~kW}$ are distributed over the surface area of the waveguide. The if flux varies sinusoidally along the front and back plates with the maximum at the center and zero at the ends. It also varies sinusoidally along the sides with the maximum in the middle. The center vane receives the same maximum flux as the back plate [1]. The of flux on the front plate is on both sides and is doubled between the windows where the surface area has been decreased. The bumpers and side walls are exposed to a toroidal particle flux of $2 \mathrm{~kW} / \mathrm{cm}^{2 *} \mathrm{e}^{(-x / 4 \mathrm{~mm})}$, where $x$ is measured radially from the leading edge of the bumpers.
During bakeout, the stainless steel FWG will expand $8.1 \mathrm{~mm}$ in length; an Inconel $625 \mathrm{FWG}$ will expand only about $5.4 \mathrm{~mm}$. The FWG is not constrained from this growth, and the expansion will not present any thermal stresses. In fact, the heaters can be used during operation to raise the temperature of the FWG, thereby moving the front face closer to the plasma.

The peak rf heat flux is approximately four times the average flux of total heat divided by total surface area. This 4.0-W/ $\mathrm{cm}^{2}$ flux occurs on the front and back faces of the front plate. Total flux on the front face, including plasma flux and if losses, is $34 \mathrm{~W} / \mathrm{cm}^{2}$. With an initial temperature of $21^{\circ} \mathrm{C}$, the front surface temperature is $145^{\circ} \mathrm{C}$ at the end of the 5-s pulse. The plate temperature equilibrates in $22 \mathrm{~s}$. Assuming no radiation and regular pulses at 20 -min intervals, the plate would reach a maximum of $160^{\circ} \mathrm{C}$ in $8 \mathrm{~h}$.

The center vane receives a maximum of twice the average if loss and no plasma flux. This $2 \mathrm{~W} / \mathrm{cm}^{2}$ on both sides causes a surface temperature rise of $10^{\circ} \mathrm{C}$ at the end of the 5-s pulse; the temperature equilibrates in $1.4 \mathrm{~s}$. Assuming no radiation and regular pulses at 20-min intervals, the center vane would reach a maximum of $226^{\circ} \mathrm{C}$ in $8 \mathrm{~h}$.

The toroidal flux impinging on the bumpers is a particle flux. Only the component normal to the surface is effective as a heat flux. The 12.7-mm-thick bumpers have full radiuses on the front outside corner. With the FWG fully inserted, the peak temperature after ten $5-\mathrm{s}$ pulses is $1350^{\circ} \mathrm{C}$. TZM starts to recrystallize at $1400^{\circ} \mathrm{C}$. If the pulse is restricted to $2 \mathrm{~s}$, the peak temperature is reduced to $858^{\circ} \mathrm{C}$ after five pulses. With the FWG pulled back $4 \mathrm{~mm}$ and subjected to the 5 -s pulse, the peak temperature is $417^{\circ} \mathrm{C}$ after seven pulses. The bumper analysis includes the assumptions that there is radiation from the outside wall only with an emissivity of 0.8 and that there is no conduction across the bolted joint.

\section{REFERENCES}

[1] T. Bigelow et al., "RF modeling and design of a folded waveguide ICRF launcher for Alcator C-MOD tokamak," Proceedings of the IEEENPS Symposium on Fusion Engineering, Hyannis, Massachusetts, Oct. 11-15, 1993. 

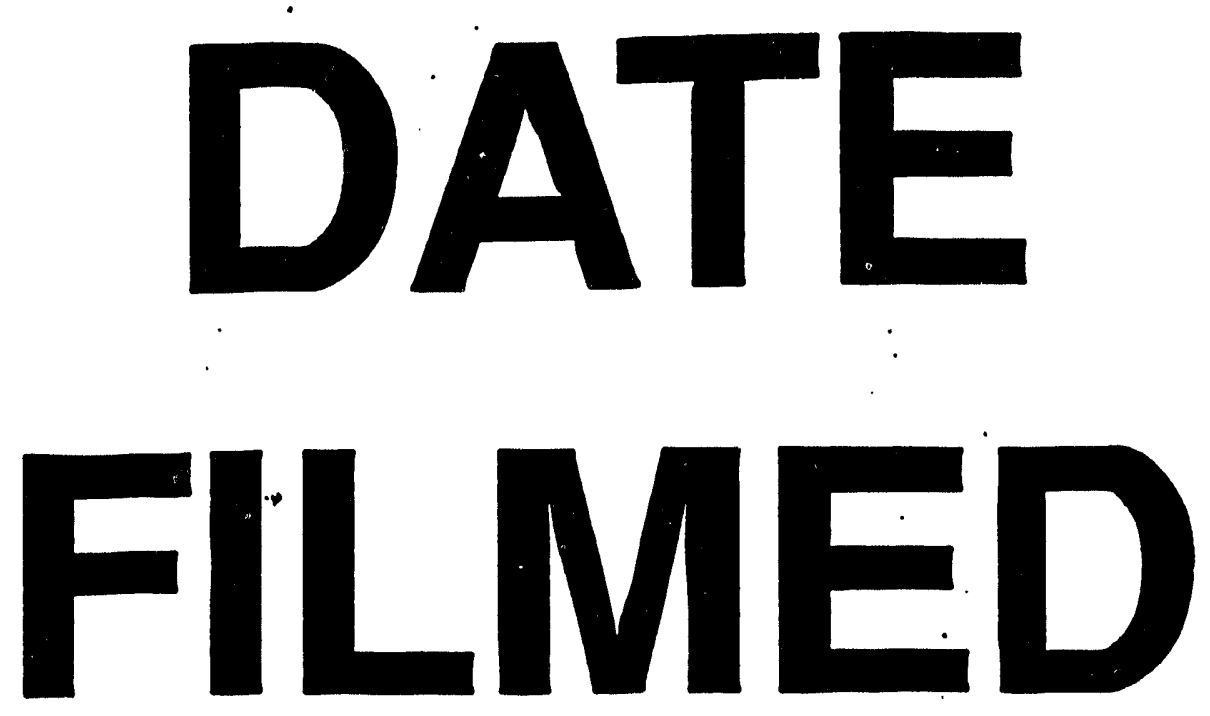

$1 / 24 / 94$
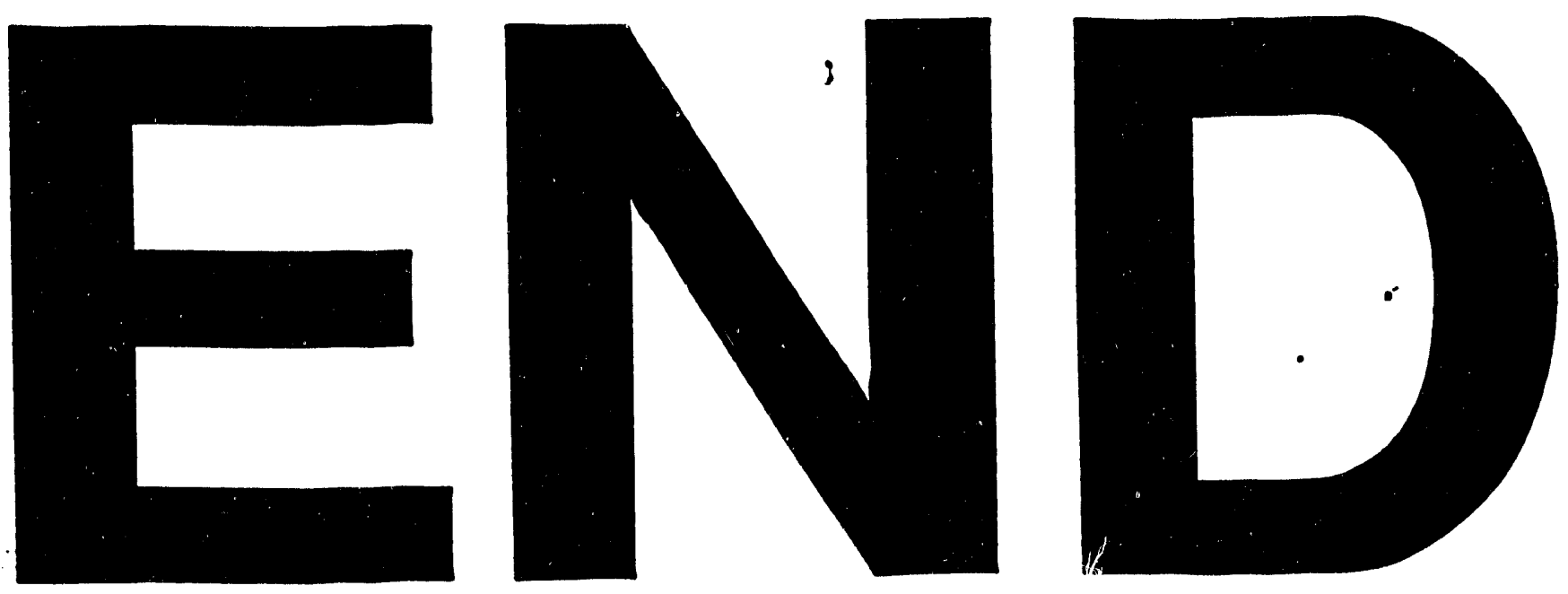
